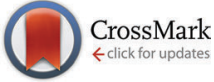

Cite this: Chem. Commun., 2015, 51, 16486

Received 19th August 2015, Accepted 23rd September 2015

DOI: $10.1039 / c 5 c c 06983 a$

www.rsc.org/chemcomm

\section{NanoSIMS analysis of an isotopically labelled organometallic ruthenium(II) drug to probe its distribution and state in vitro}

\author{
Ronald F. S. Lee, ${ }^{a}$ Stéphane Escrig, ${ }^{b}$ Marie Croisier, ${ }^{c}$ Stéphanie Clerc-Rosset, ${ }^{c}$ \\ Graham W. Knott, ${ }^{c}$ Anders Meibom, ${ }^{\text {bd }}$ Curt A. Davey, ${ }^{e}$ Kai Johnsson ${ }^{a}$ and \\ Paul J. Dyson*a
}

\begin{abstract}
The in vitro inter- and intra-cellular distribution of an isotopically labelled ruthenium(II)-arene (RAPTA) anti-metastatic compound in human ovarian cancer cells was imaged using nano-scale secondary ion mass spectrometry (NanoSIMS). Ultra-high resolution isotopic images of ${ }^{13} \mathrm{C},{ }^{15} \mathrm{~N}$, and Ru indicate that the phosphine ligand remains coordinated to the ruthenium(II) ion whereas the arene detaches. The complex localizes mainly on the membrane or at the interface between cells which correlates with its antimetastatic effects.
\end{abstract}

Ruthenium based anti-tumor compounds are under development as alternatives to classical platinum based drugs, the latter being widely used in the clinic, but are limited by resistance and severe side-effects. ${ }^{1-4}$ Among the various types of ruthenium compounds under investigation are the bifunctional ruthenium(II)arene (RAPTA) complexes, a class of organometallic ruthenium(II) complexes with a monodentate 1,2,5-triaza-7-phosphatricyclo[3.3.1.1.]decane (PTA) ligand (Fig. 1). The lead RAPTA compounds possess attractive anti-metastatic ${ }^{5}$ and anti-angiogenic ${ }^{6}$ properties. Although a number of intracellular targets have been identified for this class of compounds, ${ }^{7-9}$ the full mechanism of action remains to be elucidated and, understanding

\footnotetext{
${ }^{a}$ Institute of Chemical Sciences and Engineering, Ecole Polytechnique Fédérale de Lausanne (EPFL), CH-1015 Lausanne, Switzerland. E-mail: paul.dyson@epfl.ch; Tel: +41216939854

${ }^{b}$ Laboratory for Biological Geochemistry, Ecole Polytechnique Fédérale de Lausanne (EPFL), CH-1015 Lausanne, Switzerland. E-mail: anders.meibom@epfl.ch; Tel: +41216938015

${ }^{c}$ Interdisciplinary Centre for Electron Microscopy, Ecole Polytechnique Fédérale de Lausanne (EPFL), CH-1015 Lausanne, Switzerland. E-mail: graham.knott@epfl.ch; Tel: +41216930962

${ }^{d}$ Center for Advanced Surface Analysis, Institute of Earth Sciences, University of Lausanne, CH-1015 Lausanne, Switzerland

${ }^{e}$ Division of Structural Biology and Biochemistry, School of Biological Sciences, Nanyang Technological University, 60 Nanyang Drive, Singapore 637551, Singapore

$\dagger$ Electronic supplementary information (ESI) available: Nano-SIMS data, cell culture and sample preparation, and nano-SIMS parameter settings. See DOI: $10.1039 / \mathrm{c} 5 \mathrm{cc} 06983 \mathrm{a}$
}

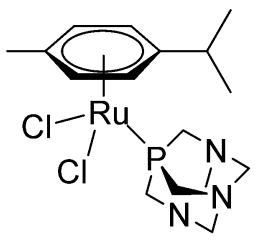

RAPTA-C

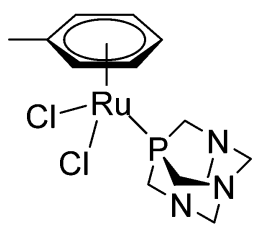

RAPTA-T
Fig. 1 Examples of RAPTA complexes.

the relative magnitude of extra- and intracellular accumulation and distribution would be useful in this respect. Previous attempts to elucidate the distribution of RAPTA complexes utilizing an anthracene florophore ${ }^{10}$ or an acetal functionalized arene ${ }^{11}$ were only moderately successful owing partly to the need for significant structural modifications to the parent molecule. Here, we describe the use of NanoSIMS to detect ruthenium and isotopically labelled ligands bound to the ruthenium center in $\mathrm{Ru}\left(\eta^{6}\right.$-toluene)(PTA)Cl $\mathrm{Cl}_{2}$ (RAPTA-T, Fig. 1).

NanoSIMS has previously been used to detect $\mathrm{Au}^{12,13}$ and $\mathrm{Pt}^{14,15}$ metal-based drugs in cells, demonstrating its potential in applications of determining the distribution of these class of compounds in vitro. NanoSIMS provides a spatial resolution of up to $50 \mathrm{~nm}$ and is able to detect up to 7 masses simultaneously at high mass-resolution. For example, in this study, we simultaneously detected the ions ${ }^{12} \mathrm{C}_{2}{ }^{-},{ }^{13} \mathrm{C}^{12} \mathrm{C}^{-},{ }^{14} \mathrm{~N}^{12} \mathrm{C}^{-},{ }^{15} \mathrm{~N}^{12} \mathrm{C}^{-},{ }^{31} \mathrm{P}^{-}$, ${ }^{32} \mathrm{~S}^{-}$and ${ }^{102} \mathrm{Ru}^{-}$. This capability allows the cellular distribution of non-essential and/or isotopically labelled elements to be mapped in vitro. The major obstacles to imaging heavy metal elements in cells with NanoSIMS are the often relatively low ionization yield and the loss of compounds of interest from cells during the sample preparation procedures required for NanoSIMS analysis. ${ }^{16}$

In this study, a cisplatin resistant ovarian cancer cell line (A2780CR) was exposed to $500 \mu \mathrm{M}$ of isotopically labelled RAPTA-T (enriched with 6 atoms of ${ }^{13} \mathrm{C}$ at the $\eta^{6}$-toluene, and 3 atoms of ${ }^{15} \mathrm{~N}$ at the PTA) for 24 hours. Subsequently the cells were fixed and prepared for NanoSIMS imaging as semi-thin sections (see ESI $\dagger$ for more details). 
In order to image the distribution of ${ }^{13} \mathrm{C},{ }^{15} \mathrm{~N}$, and $\mathrm{Ru}$ and thus to visualize where in cells the RAPTA-T molecules located, and if they stay intact, using the NanoSIMS we sputtered semithin sections with a primary $\mathrm{Cs}^{+}$-beam current around $4 \mathrm{pA}$ and a probe size of $\sim 150 \mu \mathrm{m}$ (see ESI $\dagger$ for details) for a scanning time of ca. 22 hours, corresponding to 120 consecutive images with $256 \times 256$ pixels over an area of $30 \times 30 \mu \mathrm{m}^{2} \cdot{ }^{102} \mathrm{Ru}^{-}$ counts steadily increased with time, plateauing around 8 hours ( $\sim 40$ planes) into the analysis (Fig. S2, ESI $\dagger$ ), demonstrating that a large dose of $\mathrm{Cs}^{+}$implantation is required before efficient ionization of ${ }^{102} \mathrm{Ru}^{-}$is achieved. Such long analysis times represent a severe challenge with respect to machine stability. For example, even small thermal perturbations can cause the instrument, and hence the images, to drift. By minimizing any thermal perturbation to the instrument for over one week (including not entering the lab-space around the instrument), we obtained an image drift totaling only 6 pixels during the 22 hours acquisition period, corresponding to 0.7 microns. Such stable instrument conditions make it possible to add all images together with a minimum of drift correction, and thus obtain clear total images of even very weak signals.

Fig. 2 shows the elemental distribution maps obtained from a resin-embedded section of A2780CR cells after 24 hours exposure to $500 \mu \mathrm{M}$ of isotopically labelled RAPTA-T. Highly resolved images of ${ }^{14} \mathrm{~N}^{12} \mathrm{C}^{-},{ }^{32} \mathrm{~S}^{-}$, and ${ }^{31} \mathrm{P}^{-}$allow clear visualization of the cellular compartments of the cell (labelled in Fig. 3B). The ${ }^{13} \mathrm{C} /{ }^{12} \mathrm{C}$ map shows faint variations in the ${ }^{13} \mathrm{C} /{ }^{12} \mathrm{C}$ between cell interiors and the adjacent epoxy resin (also observed in untreated controls, Fig. S1, ESI $\dagger$ ), but no clear enrichments that can be ascribed to the presence of isotopically labeled RAPTA-T molecules, or its subcomponents. This absence of discernable ${ }^{13} \mathrm{C}$ enrichment in regions clearly enriched in ${ }^{15} \mathrm{~N}$ and $\mathrm{Ru}$ (Fig. 2 and 4) could indicate that sample preparation (which includes epoxy embedding) dilutes the ${ }^{13} \mathrm{C}$-isotopic enrichment from the ${ }^{13} \mathrm{C}$-enriched $\eta^{6}$-toluene ligands to below detection limit of the NanoSIMS. ${ }^{17}$ However, given the strength of the ${ }^{15} \mathrm{~N}$ enrichment observed (Fig. 2 and 4), the presence of the corresponding ${ }^{13} \mathrm{C}$-enriched $\eta^{6}$-toluene ligands should be visible in these NanoSIMS ${ }^{13} \mathrm{C} /{ }^{12} \mathrm{C}$ images, which would reveal ${ }^{13} \mathrm{C}$-enrichment anomalies down to about $30 \%$. Thus, it is not unreasonable to hypothesize that the ${ }^{13} \mathrm{C}$-enriched $\eta^{6}$-toluene ligands have partially detached from the complex and have been diluted over the sample. Indeed, dissociation of the arene has been previously observed in binding studies to isolated oligonucleotides. ${ }^{18}$ In humans, this detached toluene would undergo detoxifaction in the liver to hippuric acid which would then be excreted in the kidneys. ${ }^{19}$

On the other hand, overlaid images of ${ }^{15} \mathrm{~N} /{ }^{14} \mathrm{~N}$ and $\mathrm{Ru} / \mathrm{C}$ (Fig. 3D) and line profiles (Fig. 4B), reveal co-accumulation of ${ }^{15} \mathrm{~N}$ and $\mathrm{Ru}$ indicating that the PTA ligand remains coordinated to the metal center after 24 hours. Enrichment in ${ }^{15} \mathrm{~N}$ (hereby used as a marker for RAPTA-T enrichment) is mainly seen on the cell membrane or interphase between cells (Fig. 3A-C). The observed localization of RAPTA-T indicates that interactions with membrane receptors or extracellular proteins are likely to be critical to its mode of action. In this respect, it has been
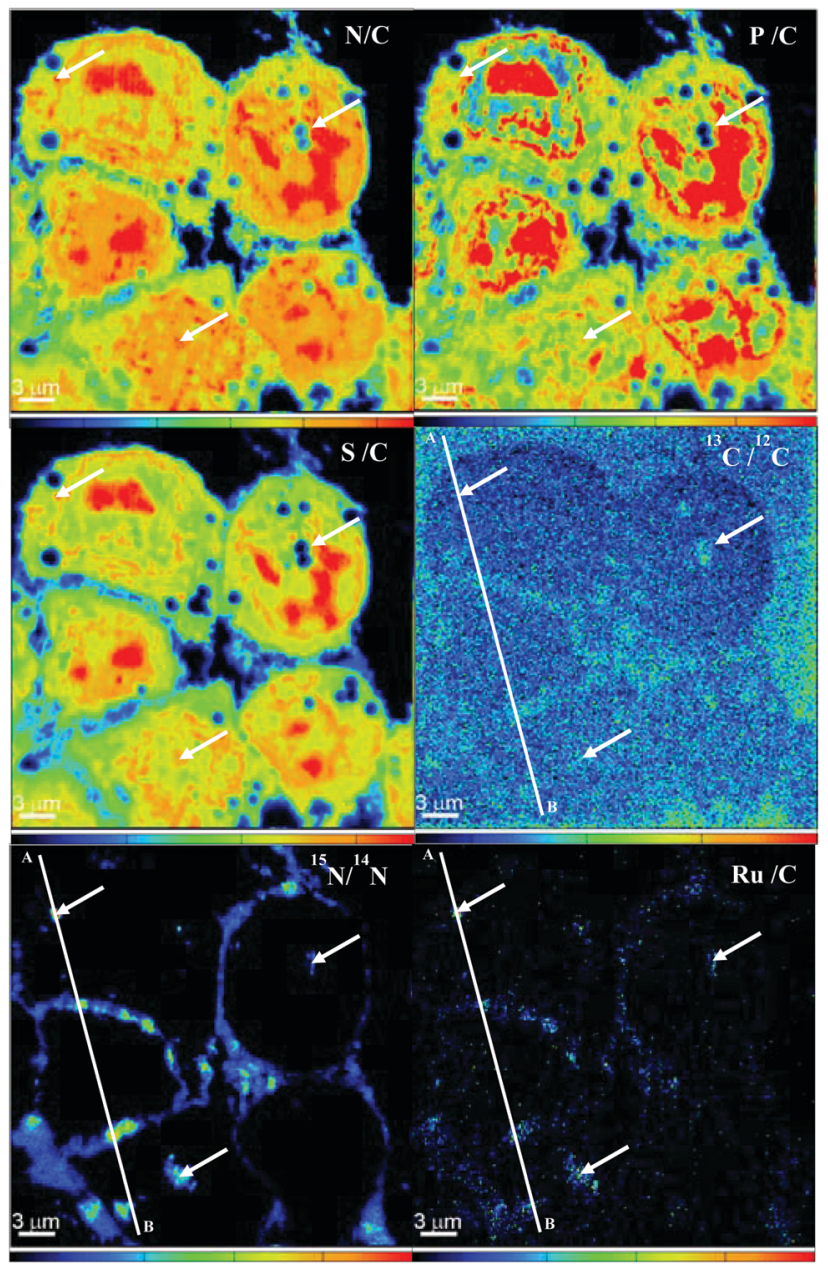

Fig. 2 Secondary ion maps of ${ }^{31} \mathrm{P}^{-} /{ }^{12} \mathrm{C}_{2}-,{ }^{32} \mathrm{~S}^{-} /{ }^{12} \mathrm{C}_{2}-,{ }^{14} \mathrm{~N}^{12} \mathrm{C}^{-} /{ }^{12} \mathrm{C}_{2}-$ ${ }^{15} \mathrm{~N}^{12} \mathrm{C}^{-} /{ }^{14} \mathrm{~N}^{12} \mathrm{C}^{-},{ }^{102} \mathrm{Ru}^{-} /{ }^{12} \mathrm{C}_{2}{ }^{-}$and ${ }^{13} \mathrm{C}^{12} \mathrm{C}^{-} /{ }^{12} \mathrm{C}_{2}{ }^{-}$(figure labels have been simplified) in A2780CR cells treated with ${ }^{15} \mathrm{~N}$ and ${ }^{13} \mathrm{C}$-labelled RAPTA-T (500 $\mu \mathrm{M}, 24$ hours). White line (AB) represents the line profile shown in Fig. 4. The ${ }^{31} \mathrm{P}^{-} /{ }^{12} \mathrm{C}_{2}{ }^{-},{ }^{32} \mathrm{~S}^{-} /{ }^{12} \mathrm{C}_{2}{ }^{-},{ }^{14} \mathrm{~N}^{12} \mathrm{C}^{-} /{ }^{12} \mathrm{C}_{2}{ }^{-}$maps allows identification of cellular compartments. Clear ${ }^{15} \mathrm{~N}$ and Ru enrichments are observed corresponding to RAPTA-T. No significant ${ }^{13} \mathrm{C}$ enrichment (above the ${ }^{13} \mathrm{C} /{ }^{12} \mathrm{C}$ ratio of the epoxy resin) is observed.

previously shown that RAPTA-T interacts with cell adhesion proteins such as fibronectin and collagen IV preventing detachment and re-adhesion of metastatic tumor cells. ${ }^{20,21}$

Only small pockets of ${ }^{102} \mathrm{Ru}^{-}$were observed inside the cells, (Fig. 2, arrows). From the cellular compartments identified (Fig. 3B), these pockets seem to lie generally within the nuclear region of the cells which is likely as RAPTA complexes have been shown to bind to histones. ${ }^{7,8}$ However, the exact subcellular localization cannot be determined accurately without correlated electron microscope imaging. The lack of correlation between these ${ }^{102} \mathrm{Ru}^{-}$hotspots and ${ }^{32} \mathrm{~S}^{-}$shows that RAPTA-T distributes differently to cisplatin, which was found to accumulate in the nucleolus and S-rich regions of the cells. ${ }^{14}$ This difference is not unexpected considering the contrasting in vitro and in vivo anti-tumor effects of cisplatin and RAPTA-T, respectively. The observed distribution pattern is in reasonable agreement with cell uptake studies of RAPTA-T in A2780 CR cells, ${ }^{22}$ 


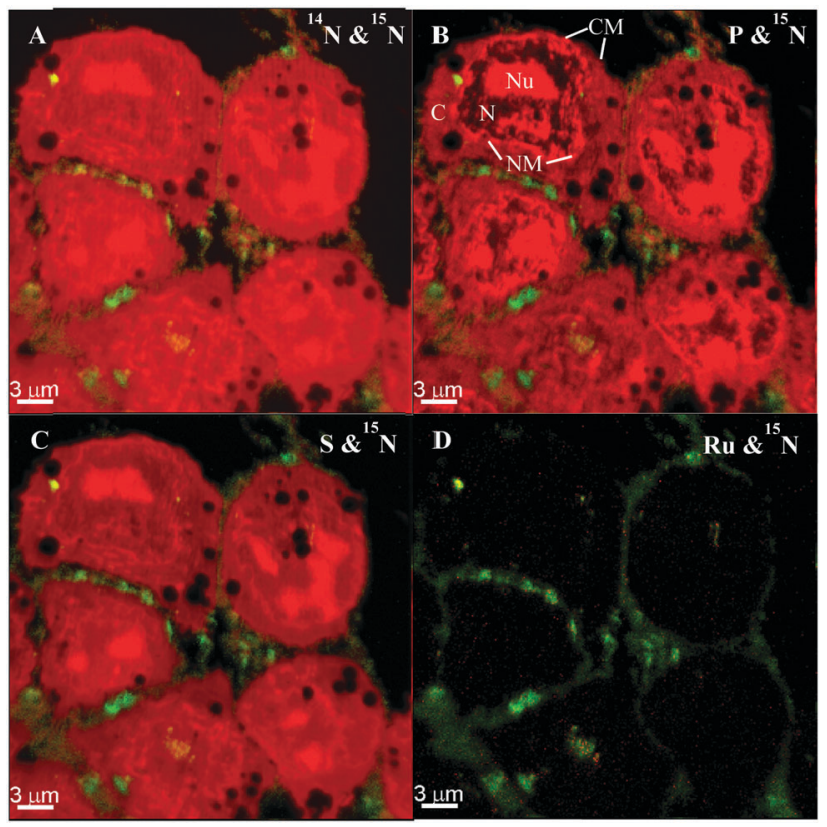

Fig. 3 Composite RBG images of semi thin sections of $A 2780 C R$ cells treated with ${ }^{15} \mathrm{~N}$ and ${ }^{13} \mathrm{C}$ labelled RAPTA-T (500 $\mu \mathrm{M}, 24$ hours). ${ }^{15} \mathrm{~N}^{12} \mathrm{C}^{-} /{ }^{14} \mathrm{~N}^{12} \mathrm{C}^{-}$ is coloured green and ${ }^{31} \mathrm{P}^{-} /{ }^{12} \mathrm{C}_{2}{ }^{-},{ }^{32} \mathrm{~S}^{-} /{ }^{12} \mathrm{C}_{2}{ }^{-},{ }^{14} \mathrm{~N}^{12} \mathrm{C}^{-} /{ }^{12} \mathrm{C}_{2}^{-}$and ${ }^{102} \mathrm{Ru}^{-} /$ ${ }^{12} \mathrm{C}_{2}{ }^{-}$is coloured red (figure labels have been simplified). Subcellular compartments $\mathrm{N}$ (nucleus), Nu (nucleolus), C (cytoplasm), NM (nuclear membrane) and CM (cell membrane) have been labelled in image $\mathrm{B}$. The ${ }^{102} \mathrm{Ru}^{-} /{ }^{12} \mathrm{C}_{2}{ }^{-}$and ${ }^{15} \mathrm{~N}^{12} \mathrm{C}^{-} /{ }^{14} \mathrm{~N}^{12} \mathrm{C}^{-}$images show clear co-accumulation of both $\mathrm{Ru} \&{ }^{15} \mathrm{~N}$. RAPTA-T seems to localize on the cell membrane and between cells and its accumulation does not appear correlated with that of $\mathrm{P}, \mathrm{S}$ or $\mathrm{N}$.

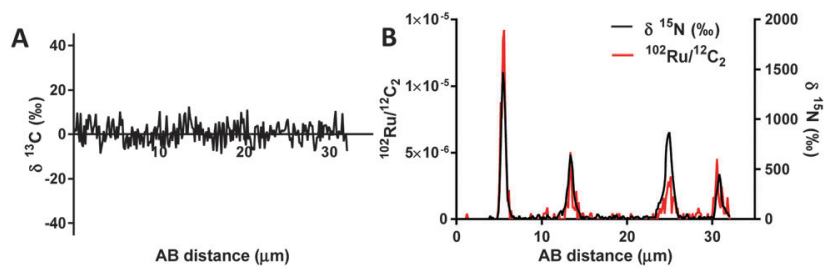

Fig. 4 Line profiles of ${ }^{13} \mathrm{C}^{12} \mathrm{C}^{-} /{ }^{12} \mathrm{C}_{2}{ }^{-}$(A) and overlaid line profile of ${ }^{15} \mathrm{~N}^{12} \mathrm{C}^{-} /{ }^{14} \mathrm{~N}^{12} \mathrm{C}^{-}$and ${ }^{102} \mathrm{Ru}^{-} /{ }^{12} \mathrm{C}_{2}^{-}$(B) across line $\mathrm{AB}$ (shown in Fig. 2). Four clear peaks of ${ }^{15} \mathrm{~N}^{12} \mathrm{C}^{-} /{ }^{14} \mathrm{~N}^{12} \mathrm{C}^{-}$and ${ }^{102} \mathrm{Ru}^{-} /{ }^{12} \mathrm{C}_{2}-$ are seen correlating perfectly, demonstrating the co-enrichment of ${ }^{15} \mathrm{~N}$ and Ru. In contrast, the ${ }^{13} \mathrm{C}^{12} \mathrm{C}^{-} / \mathrm{C}_{2}{ }^{-}$ratio show no enrichment above the statistical noise level.

where ruthenium was found in the membrane as well as the particulate, cytoskeletal and nuclear fractions upon similar treatment conditions.

From our data, the observed co-accumulation of ${ }^{15} \mathrm{~N}$ and $\mathrm{Ru}$ shows that the PTA ligand remains coordinated to the ruthenium ion. This result highlights one of the key strengths of NanoSIMS for the detection of metal-based drugs, i.e. that the stability/liability of the ligands coordinated to the metal center can be probed via isotopic labelling. The ability to differentiate between the accumulation of a compound on the membrane versus intracellular accumulation in specific organelles illustrates the utility of the NanoSIMS relative to other techniques used to probe metallodrug distribution, such as inductively coupled plasma mass spectrometry and atomic absorption spectroscopy, ${ }^{2-25}$ where such a spatial distinction cannot be made without cell fractionation, a process likely to introduce other distribution artifacts.

With recent developments in NanoSIMS, the technique has emerged as a powerful tool for exploring the distribution of metal-based drugs in cells, combining high sensitivity of detection with the ability to study the state of metal-bound ligands following appropriate isotopic labelling. In the case of RAPTA-T, the liability of the $\eta^{6}$-toluene ligand presumably acts, in addition to aquation, as an activation mechanism of the compound, although from the data the extent of detachment is difficult to assess. Moreover, the observed accumulation of $\mathrm{Ru}$ on the membrane or at the interface between cells is in agreement with a number of in vitro and in vivo properties of RAPTA-T ${ }^{22,26}$ and provides further insight into the drugs mechanism of action.

This research was supported by the NCCR Chemical Biology, funded by the Swiss National Science Foundation.

\section{Notes and references}

1 M. A. Jakupec, M. Galanski, V. B. Arion, C. G. Hartinger and B. K. Keppler, Dalton Trans., 2008, 183-194.

2 E. Reisner, V. B. Arion, B. K. Keppler and A. J. L. Pombeiro, Inorg. Chim. Acta, 2008, 361, 1569-1583.

3 A. Bergamo, C. Gaiddon, J. H. M. Schellens, J. H. Beijnen and G. Sava, J. Inorg. Biochem., 2012, 106, 90-99.

4 M. Groessl and C. G. Hartinger, Anal. Bioanal. Chem., 2012, 405, 1791-1808.

5 C. Scolaro, A. Bergamo, L. Brescacin, R. Delfino, M. Cocchietto, G. Laurenczy, T. J. Geldbach, G. Sava and P. J. Dyson, J. Med. Chem., 2005, 48, 4161-4171.

6 A. Weiss, R. H. Berndsen, M. Dubois, C. Müller, R. Schibli, A. W. Griffioen, P. J. Dyson and P. Nowak-Sliwinska, Chem. Sci., 2014, 5, 4742-4748.

7 Z. Adhireksan, G. E. Davey, P. Campomanes, M. Groessl, C. M. Clavel, H. Yu, A. A. Nazarov, C. H. F. Yeo, W. H. Ang, P. Dröge, U. Rothlisberger, P. J. Dyson and C. A. Davey, Nat. Commun., 2014, 5,3462 .

8 B. Wu, M. S. Ong, M. Groessl, Z. Adhireksan, C. G. Hartinger, P. J. Dyson and C. A. Davey, Chem. - Eur. J., 2011, 17, 3562-3566.

9 M. V. Babak, S. M. Meier, K. V. M. Huber, J. Reynisson, A. A. Legin, M. A. Jakupec, A. Roller, A. Stukalov, M. Gridling, K. L. Bennett, J. Colinge, W. Berger, P. J. Dyson, G. Superti-Furga, B. K. Keppler and C. G. Hartinger, Chem. Sci., 2015, 6, 2449-2456.

10 A. A. Nazarov, J. Risse, W. H. Ang, F. Schmitt, O. Zava, A. Ruggi, M. Groessl, R. Scopelitti, L. Juillerat-Jeanneret, C. G. Hartinger and P. J. Dyson, Inorg. Chem., 2012, 51, 3633-3639.

11 Y. Q. Tan, P. J. Dyson and W. H. Ang, Organometallics, 2011, 30, 5965-5971.

12 L. E. Wedlock, M. R. Kilburn, J. B. Cliff, L. Filgueira, M. Saunders and S. J. Berners-Price, Metallomics, 2011, 3, 917-925.

13 L. E. Wedlock and S. J. Berners-Price, Aust. J. Chem., 2011, 64, 692-704.

14 A. A. Legin, A. Schintlmeister, M. A. Jakupec, M. Galanski, I. Lichtscheidl, M. Wagner and B. K. Keppler, Chem. Sci., 2014, 5, 3135-3143.

15 L. E. Wedlock, M. R. Kilburn, R. Liu, J. A. Shaw, S. J. Berners-Price and N. P. Farrell, Chem. Commun., 2013, 49, 6944-6946.

16 P. Hoppe, S. Cohen and A. Meibom, Geostand. Geoanal. Res., 2013, 37, 111-154.

17 S. H. Kopf, S. E. McGlynn, A. Green-Saxena, Y. Guan, D. K. Newman and V. J. Orphan, Environ. Microbiol., 2015, 17, 2542-2556.

18 A. Dorcier, P. J. Dyson, C. Gossens, U. Rothlisberger, R. Scopelliti and I. Tavernelli, Organometallics, 2005, 24, 2114-2123.

19 L. Flowers, W. Boyes, S. Foster, M. Gehlhaus, K. Hogan, A. Marcus, P. McClure and M. Osier, U. S. Environ. Prot. Agency, 2005, 1-107. 
20 A. Bergamo, A. Masi, P. J. Dyson and G. Sava, Int. J. Oncol., 2008, 1281-1289.

21 P. Nowak-Sliwinska, J. R. van Beijnum, A. Casini, A. A. Nazarov, G. Wagnières, H. van den Bergh, P. J. Dyson and A. W. Griffioen, J. Med. Chem., 2011, 54, 3895-3902.

22 D. A. Wolters, M. Stefanopoulou, P. J. Dyson and M. Groessl, Metallomics, 2012, 4, 1185.
23 M. Groessl, O. Zava and P. J. Dyson, Metallomics, 2011, 3, 591-599. 24 A. R. Timerbaev, J. Anal. At. Spectrom., 2014, 29, 1058-1072.

25 A. Zayed, T. Shoeib, S. E. Taylor, G. D. D. Jones, A. L. Thomas, J. P. Wood, H. J. Reid and B. L. Sharp, Int. J. Mass Spectrom., 2011, 307, 70-78.

26 A. Bergamo, A. Masi, P. J. Dyson and G. Sava, Int. J. Oncol., 2008, 33, 1281-1289. 